\title{
O EMPREENDEDORISMO E AS NOVAS PRÁTICAS DO FAZER CIENTÍFICO
}

Leonardo de Lucas da Silva Domingues

\section{RESUMO}

O trabalho versa sobre a transformação do fazer científico de pesquisadores em universidades públicas brasileiras no contexto atual. Parte-se da premissa de que tais modificações se vinculam, de maneira significativa, a um processo que se acentuou recentemente nas instituições de ensino superior: a penetração da cultura do empreendedorismo na organização e na interação da prática científica. Por conta disso, verifica-se uma modificação das noções normalmente associadas a pesquisadores e cientistas. Ser bem-sucedido, ter liderança e ter reconhecimento no campo econômico e no campo social passam a ser muito visados. Os pesquisadores, nesse movimento, projetam-se cada vez mais no perfil do empresário de ascensão acelerada que soube fazer grandes negócios com o ramo da ciência. Um exemplo dessa argumentação pode ser visto na influência exercida pelas incubadoras de empresas.

Palavras-chave: Atividade Científica; Ciência; Cultura Empresarial

\section{ENTREPRENEURSHIP AND NEW PRACTICES OF SCIENTIFIC}

\begin{abstract}
The work deals with the transformation of scientific research in Brazilian public universities in the current context. It starts with the premise that such changes are linked, significantly, a process that has accelerated recently on higher education institutions: the penetration of the culture of entrepreneurship in the organization and interaction of scientific practice. Because of this, there is a modification of the terms normally associated with scientists and researchers. To be successful, have leadership and be recognized in the economic and social field become very concerned. The researchers in this movement, design is becoming more the profile of the entrepreneur who knew of accelerated ascension do serious business with the branch of science. An example of this argument can be seen in the influence exerted by business incubators.
\end{abstract}

Keywords: scientific activity; science; business culture 


\title{
Introdução
}

\begin{abstract}
Temas recorrentes assumem outros significados, como a autonomia, e palavras que adquiriram sentido em outras esferas são transpostas para o discurso universitário, como produtividade, qualidade, competitividade, flexibilidade, gestão e gestores, eficiência e empreendedorismo. [...] $\mathrm{O}$ metro que poderia aferir todas essas "qualidades" deixa de ser um determinado "ethos" acadêmico, tomando emprestado um outro sistema de medida: o mercado. Assim, a aferição é feita a partir de noções como produtividade, eficiência, excelência, flexibilidade e empreendedorismo. [...] um novo ethos se impõe, o capitalismo acadêmico (FILHO, et al., 2004, p. 43).
\end{abstract}

Nos últimos anos, o fenômeno do empreendedorismo ganhou significativo destaque entre os meios de comunicação e no âmbito acadêmico. Empreender passou a ser não só função de pessoas envolvidas com a atividade econômica, mas, também, tornou-se um norte para vários segmentos da vida social, inclusive universitários. Em alguns aspectos, o tema foi apresentado quase como uma possível panaceia para os problemas estruturais brasileiros.

As questões referentes a esse assunto, que anteriormente eram objeto de discussão principalmente da área da Administração, atualmente, encontram espaço privilegiado em outros campos do conhecimento, em políticas públicas dos governos, e em ações de institutos e organizações não governamentais ${ }^{1}$. O estudo sobre o tema é muito novo, sendo possível dizer que detém pouco mais de duas décadas.

Além disso, um dos campos de muita atuação e de especial interesse dos autores que tratam sobre o fenômeno é a universidade. Esta, de meio produtor/formulador de muitas das concepções sobre o tema, principalmente na Administração, passou a ser terreno fértil para pôr em prática os aspectos que permeiam o conhecimento empreendedor. O ponto-chave desse processo é o da transformação de cientistas/pesquisadores/professores em empreendedores, que encontraram na ciência um potente meio de fazer bons negócios.

\section{Empreendedorismo como solução, como resposta e como saída para diversos problemas: o entusiasmo pela "revolução silenciosa"}

\footnotetext{
${ }^{1}$ Um exemplo é a Semana Global do Empreendedorismo, evento com boa cobertura da impressa brasileira. A iniciativa é do Instituto Endeavor, da Kauffman Foundation e da Enterprise UK. A Semana é promovida com a intenção de "despertar a atitude empreendedora nas pessoas", tendo como noção de que a atitude empreendedora é a capacidade de "pensar fora da caixa", de "ser proativo", de "ter um sonho grande" e de "fazer de tudo para realizá-lo" (Disponível em: http://www.semanaglobal.org.br/ . Acesso: 20 nov. 2009).
}

INTRATEXTOS, Rio de Janeiro, 4(1): 137-159, 2012.

Página 138 
Peter Drucker escreve Inovação e espírito empreendedor na primeira metade da década de 1980 e percebe que desde o começo dos anos 70 modificações profundas estavam ocorrendo na economia dos Estados Unidos. Para o autor, essas transformações redirecionaram a economia de "gerencial" para "empreendedora". E o que possibilitou essa mudança foram as novas aplicações da Administração aos novos e pequenos empreendimentos, seguindo o princípio da inovação sistemática (busca e aproveitamento de novas oportunidades para satisfazer carências e necessidades humanas).

As três últimas décadas marcam, para alguns autores (DOLABELA, 1999b; DORNELAS, 2001), o início de uma nova era, a era do empreendedorismo, também conhecida como a revolução do empreendedorismo. Uma frase de Jeffry Timmons expressa bem esse sentido: "O empreendedorismo é uma revolução silenciosa, que será para o século XXI mais do que a revolução industrial foi para o século XX” (TIMMONS, 2001, p. 10, tradução nossa). Essa nova era toma corpo, principalmente, pela ação dos empreendedores.

Dornelas ressalta:

[...] são os empreendedores que estão eliminando barreiras comerciais e culturais, encurtando distâncias, globalizando e renovando os conceitos econômicos, criando novas relações de trabalho e novos empregos, quebrando paradigmas e gerando riqueza para a sociedade (DORNELAS, 2001, p. 21).

Uma parte da literatura, em conjunto com essas características, vincula essas transformações com algumas ideias que ganham repercussão atualmente como: sociedade/era da informática, sociedade/era do conhecimento, sociedade em rede, etc. A ascensão da internet, o triunfo do mercado (globalização), a reestruturação produtiva, entre outras questões, encontram destaque como aspectos positivos de um grande processo de modificação da sociedade rumo à expansão das atividades empreendedoras.

A chamada nova economia, a era da internet, tem mostrado que boas idéias inovadoras, know-how, um bom planejamento e, principalmente, uma equipe motivada, são ingredientes poderosos que, quando somados no momento adequado, acrescidos do combustível indispensável à criação de novos negócios - capital podem gerar negócios grandiosos em curto espaço de tempo. Isso era inconcebível há alguns anos. O contexto atual é propício para o surgimento de um número cada vez maior de empreendedores (DORNELAS, 2001, p. 21).

A base de todas essas perspectivas sobre a constituição de uma era do empreendedorismo são os casos de pequenas empresas de base tecnológica que constituíram 
muita riqueza em pouco tempo. Os exemplos ressaltados na literatura são numerosos: Microsoft, Google, eBay, Yahoo!, Dell Computer, etc. A ideia tentadora e convidativa de ser um novo Bill Gates é que impulsiona o interesse atualmente dispensado ao tema, principalmente nos meios de comunicação.

\section{A crítica ao entusiasmo}

O pensamento liberal clássico, segundo Cêa e Luz (2006), é a base das concepções que constituem o empreendedorismo: em Adam Smith tem-se a valorização do homem frugal e industrioso; em John Locke encontra-se a aposta no interesse individual como a origem do bem comum (os impulsos egoístas concorrem para o bem comum). Segundo Cêa e Luz (2006), o empreendedorismo também adota os seguintes preceitos liberais: o de que é preciso compreender o sistema econômico a partir das ações individuais dos empreendedores, e o de identificar o individualismo como mola propulsora do desenvolvimento (CÊA; LUZ, 2006).

Além disso, para Cêa e Luz (2006) o empreendedorismo estimula uma visão idealista de mundo, em que o sonho precede o real e que o ideal concretiza o real. Essa é a tônica que explica porque qualquer ser humano pode ser um empreendedor: basta ter um sonho e disposição para realizá-lo que ele se tornará realidade. Nessa forma de pensamento, o empreendedor é aquele que pode realizar seus sonhos como se a realidade fosse uma projeção da mente (CÊA; LUZ, 2006).

Os teóricos do empreendedorismo apresentam o mundo, segundo seus críticos, de maneira naturalizada. A história é a história do empreendedorismo, porque ele sempre esteve presente, de uma forma ou de outra, entre os homens. O homem, para os teóricos do empreendedorismo, sempre foi empreendedor, e sempre o será, dando uma idéia de que os princípios que movem a vida na sociedade capitalista é parte integrante da natureza humana (CÊA; LUZ, 2006).

Para Silva e Bassani (2007), o empreendedorismo, além de ter sua origem ligada ao liberalismo, ainda conta com a influência de mais duas formas de pensamento: a doutrina evolucionista (darwinismo social) e a psicologia comportamental. De cada um dos campos se destaca uma ideia que integrara o corpo do que representa o empreendedorismo: do evolucionismo vem a noção de processo de seleção natural; do liberalismo, o livre-arbítrio e a vontade; e, da psicologia comportamental, a teoria dos traços de personalidade. Segundo os 
autores, “[...] juntos, constroem (talvez de forma subliminar) um conjunto suficientemente potente para se conformar em um instrumento ideológico de dominação e alienação" (SILVA; BASSANI, 2007, p. 72).

Silva e Bassani (2007) veem essa ênfase nas atitudes comportamentais dos sujeitos como condicionantes do sucesso no mundo dos negócios com grande preocupação. A ideia de oferecer receitas de sucesso às pessoas que não têm perspectivas concretas de futuro é chamada de charlatanismo pelos autores.

\begin{abstract}
A personalidade do empreendedor pode ser considerada como uma das condições necessárias para o sucesso e o arrojo do negócio, mas de maneira alguma deve ser 'vendida' como a 'tábua de salvação', ou como se existisse uma personalidade ideal para o sucesso do empreendimento (SILVA; BASSANI, 2007, p. 65).
\end{abstract}

Sobre a exaltação do perfil do empreendedor de sucesso, os autores apresentam o seguinte comentário:

As características gerais básicas descritas em quase todas as referências para definir o perfil adequado para o empresário dão pistas de um indivíduo com 'têmpera de aço’ e um nível de perspicácia comparável aos heróis das histórias em quadrinhos [...] Uma espécie de semi-deus, guru dos negócios, uma figura carismática por excelência, quase um mito (SILVA; BASSANI, 2007, p. 67).

Um fator que também desperta muitas críticas é a propagação desse tipo de discurso de possibilidade de sucesso no contexto semi-periférico brasileiro. As características de um mercado de trabalho com taxas de desemprego significativas, com crescente flexibilização e precarização das relações de trabalho, e com aumento da informalidade, constituem terreno fértil para a transformação de trabalhadores empobrecidos em empreendedores (LIMA; ARELARO, 2008), como se pode ver na passagem abaixo:

O empreendedorismo [...] passa a significar uma alternativa frente à eliminação dos empregos formais causada pela transição da tecnologia mecânica para a de teleinformação, pelo aumento da competitividade a que as empresas estão obrigadas para sobreviverem frente às inúmeras turbulências a que o mercado global está sujeito. Nesse sentido, torna-se imperativo criar o próprio emprego como alternativa de sobrevivência. Da carreira tradicional, migra-separa a carreira sem fronteiras, carreira que implica mobilidade irregular e imprevisível tanto no grau de desafio como na remuneração, carreira em que os indivíduos não recebem empregos, mas os criam e recriam a partir de suas próprias competências e na qual os sinais de progresso são ambíguos e equívocos. [...] pressupõe-se igualmente, dentro desse contexto de carreira sem fronteiras, a emergência do jovem empreendedor (GEM, 2008, p. 63).

INTRATEXTOS, Rio de Janeiro, 4(1): 137-159, 2012. 
O empreendedorismo culpabiliza as pessoas que se encontram em situações socioeconômicas precárias porque esse tipo de problema é fruto da responsabilidade própria e única do indivíduo (sua condição de vida decorre de seu comportamento e de seus valores). Assim, a condição de marginalização dos trabalhadores no novo contexto econômico tem sua base explicativa no insucesso do próprio trabalhador (LIMA; ARELALO, 2008).

A solução para os problemas acima destacados passa a depender do sucesso das iniciativas individuais de cada um (está com o sujeito a responsabilidade pelo sucesso ou fracasso do seu "sonho"), da ação do indivíduo naturalmente livre (LIMA; ARELARO, 2008). Nesse sentido, empreendedor vincula-se ao protótipo do "novo" profissional, o do empresário de si mesmo, único responsável pela sua trajetória profissional (GOUVEIA, 2006).

Além da resolução de problemas sociais ficar por conta da ação dos indivíduos isoladamente, para a visão neoliberal, desemprego e informalidade são oportunidades para o crescimento e a consolidação do empreendedorismo como meio de desenvolver a mentalidade e o comportamento do indivíduo com vistas à criação de novas empresas de pequeno porte, expandindo a atividade econômica (LIMA; ARELARO, 2008).

A propagação do ideário do empreendedorismo, além de ter forte apelo nos meios de comunicação de modo geral ${ }^{2}$, também é reforçada pela defesa e pelo estímulo que agências multilaterais, como o Banco Mundial, e de programas de representatividade internacional, como o Programa das Nações Unidas para o Desenvolvimento (PNUD) da Organização das Nações Unidas, dão ao tema (LIMA; ARELALO, 2008).

O relatório do Banco Mundial, Globalização, crescimento e pobreza: a nova onda da globalização e seus efeitos econômicos, publicado em 2002, propõe, como forma de resolução das assimetrias da nova ordem econômica, um programa de ação para inclusão econômica com destaque ao incentivo ao empreendedorismo como forma complementar das outras iniciativas de amparo social. Segundo o relatório:

Isso é importante para ajudar individualmente os trabalhadores que sofrerão perdas no curto prazo por causa da abertura da economia, como também para criar uma base social sólida [solid social foundation] sobre a qual as famílias - especialmente

\footnotetext{
${ }^{2}$ De tempos em tempos aparecem noticiais difundindo a ideia do "seja seu patrão" como um valor cultural para todas as pessoas. Exemplos: Revista Veja: A vida sem patrão, edição 1705, 20/06/2001; Revista Veja: A receita dos vencedores, edição 1745, 03/04/2002; Revista Época: O Brasil empreendedor, edição 602, 28/11/2009.
}

INTRATEXTOS, Rio de Janeiro, 4(1): 137-159, 2012. 
as mais pobres - se sintam confortáveis para correr riscos e perseguir [pursuing] o empreendedorismo (WORLD BANK, 2002, p. 120, tradução nossa).

No texto do PNUD, a iniciativa privada é avaliada como o principal agente para a redução da pobreza no mundo. Por um lado, o relatório sublinha o papel relevante que as grandes e médias empresas têm ampliando seu leque de consumidores entre as populações mais pobres, e levando, assim, melhores condições de vida a esses grupos. Por outro, o documento quer incentivar a participação dessas pessoas menos favorecidas em atividades econômicas. A ideia é “[...] desencadear o poder dos empreendedores locais para reduzir a pobreza em suas comunidades e nações" (PNUD, 2004, p. 5).

Para Lima e Arelalo (2008), esse tipo de relatório, tanto o do Banco Mundial como o do PNUD, reforça a ideia de que a mudança social e a econômica dependem de mudança na mentalidade do comportamento do indivíduo. No processo de globalização, as perdas são inevitáveis, então, o empreendedorismo precisa ser desenvolvido por meio de ações que visem a "[...] confortar os pobres, no sentido de consolar com palavras, recompensas, promessas [...] e não com projetos de redistribuição de renda que signifique diminuição da exploração do trabalho e do lucro do capital” (LIMA; ARELALO, 2008, p. 8).

Segundo Silva e Bassani (2007), as condições dos países periféricos e semiperiféricos são, em sua maioria, tão precárias no que tange ao acesso a bens necessários para uma vida digna (saúde, educação, alimentação, habitação, etc) ou se apresentam de uma forma tão desesperadora que "[...] o fomento ao investimento e a livre iniciativa torna-se mais um gesto de descompromisso social que de incentivo à produção" (SILVA; BASSANI, 2007, p. 71).

Sobre esses desesperançados aspirantes a empreendedor, Silva e Bassani (2007) destacam a seguinte indagação:

[...] é quase covarde a proposição de que se o candidato a empresário não cumprir os quesitos estabelecidos ou não se 'transformar' neles corre o risco de ser derrotado impiedosamente por si mesmo, ficando sugerido que a derrota é decorrência de suas 'fraquezas', mais do que das ferozes condições de mercado de economias atrasadas. [...] Por mais que este instrumento denominado empreendedorismo possa até mesmo ser útil em alguma situações para a melhoria de performance de interessados e necessitados não poderia ser apresentado com tanta veemência como via de acesso social confiável para indivíduos desesperados em economias igualmente desesperadas (SILVA; BASSANI, 2007, p. 72).

O empreendedorismo, segundo Lima e Arelalo (2008), foi além da ideia de simplesmente formar empresários, para se tornar um movimento amplo de pretensão a 
enraizar valores individualistas na sociedade. Por meio de várias ações, ele espalha e perpetua a disseminação da cultura empresarial a todos os âmbitos da vida social.

Paes de Paula (2000) acentua, da seguinte forma, a ampliação da influência do empreendedorismo:

Observamos atualmente uma ideologia do 'empreendedorismo', que extrapolou as
fronteiras das empresas e se espraia pela sociedade. As técnicas e idéias que antes
eram restritas ao treinamento dos gerentes, agora estão disponíveis para quem quiser
acessá-las, reforçando um culto sem culpa à personalidade e ao sucesso. Este
'empreendedorismo', além de colaborar para a exacerbação do individualismo e
originar novos grilhões, uma vez que cria uma falsa impressão de liberdade,
contribui sobremaneira para a desmobilização política, nos distanciando das
possibilidades de democratização (PAES DE PAULA, 2000, p. 10).

O discurso do empreendedorismo vem ao público de modo geral como uma novidade, e é propagando por meio de vários exemplos de sucesso, casos em que o investimento (às vezes pequeno) ou uma boa ideia rendeu enormes lucros e fatias significativas no mercado. Segundo Lima e Arelalo (2008), o empreendedorismo é anunciado como esse “[...] algo novo, resultado de uma suposta concepção moderna, que responderia aos atuais desafios sociais no campo do trabalho e do desenvolvimento" (LIMA; ARELALO, 2008, p. 9).

Lima e Arelalo (2008) acrescentam ainda que esse tipo de manifestação que atribui ao atual contexto socioeconômico o início de uma "revolução silenciosa" ou de uma "era do empreendedorismo" busca omitir no discurso empreendedor sua origem vinculada à concepção individualista (fundamentada na competição e na desigualdade), camuflando-a com uma apresentação, um rótulo de novidade.

\section{$O$ centro do entusiasmo: relação universidade-empresa}

O modelo teórico muito associado ao da relação universidade/empresa é o chamado Tripla Hélice (Triple Helix), proposto por Henry Etzkowitz. O conceito de Tripla Hélice tenta descrever e caracterizar a interação universidade-indústria-governo. Esse efeito interativo ressalta que a inovação industrial suscita novas questões para as pesquisas científicas, assim como o envolvimento da universidade na inovação industrial melhora o desempenho da pesquisa básica. $\mathrm{O}$ autor também destaca a importância do modelo para os países ditos "em desenvolvimento": "A interação universidade-empresa-governo é cada vez mais a base 
estratégica para o desenvolvimento social e econômico nas sociedades industriais desenvolvidas e também naquelas em desenvolvimento" (ETZKOWITZ, 2005, p. 2).

Essa teorização apresenta um novo papel para a universidade intitulado por Etzkowitz de "a segunda revolução acadêmica"3. Nessa concepção, a universidade assume posição importante no desenvolvimento econômico (pró-ativa) a partir da transformação da pesquisa em atividade econômica. A relevância da universidade no desenvolvimento da sociedade diz respeito a sua interação com o setor produtivo, estimulando o surgimento de ambientes de inovação e disseminando uma cultura empreendedora (ETZKOWITZ, 2002).

Para exemplificar em dados empíricos os argumentos teóricos, Etzkowitz destaca as transformações que ocorreram a partir da segunda metade do século XX em alguns centros de investigação americanos como o MIT, a Universidade de Stanford e a Universidade de Harvard. Para tais casos o autor cunhou o conceito de universidade empreendedora. Nesses casos, a universidade adquire papel de liderança da inovação tecnológica e organizacional (ETZKOWITZ, 2002).

$\mathrm{O}$ autor, em suas pesquisas, avalia a universidade empreendedora como um fenômeno emergente.

[...] isso significa que a universidade passa a ter uma visão estratégica de seu próprio desenvolvimento e de sua relação com parceiros potenciais, ao mesmo tempo, vai muito além disso. Por um lado, a relação da universidade com a sociedade muda, enquanto que, por outro, há uma renovação da estrutura interna da universidade (ETZKOWITZ, 2002, p. 2, tradução nossa).

Para Vasconcellos, Waack e Vasconcellos (1997, p. 8),

[...] com o aumento da concorrência e a globalização dos mercados, a universidade passou a ser uma fonte importante de tecnologia para obter competitividade, enquanto que as empresas se tornaram uma fonte de recursos alternativa para as universidades.

Um exemplo de modelo de tripla hélice é a incubadora de empresa de base tecnológica ${ }^{4}$. É considerada uma organização híbrida entre as relações universidade-empresagoverno e serve de espaço de interação entre elas. Para Etzkowitz (2002), a premissa das

\footnotetext{
${ }^{3}$ Para Etzkowitz (2002;2005), essa segunda revolução acadêmica representa esse momento de aproximação da universidade com a empresa. Nesse sentido, a relação com o setor produtivo passa a ser fundamental. A primeira revolução acadêmica ocorreu no final do século XVII, nos Estados Unidos, quando a pesquisa foi agregada às atividades universitárias, que até então se restringiam unicamente ao ensino.

${ }^{4}$ Para maiores informações sobre o que são as incubadoras de empresas de base tecnológica e sobre como é o processo de incubação ver: BOLTON, 1997; DOLABELA, 1999b; DOMINGUES, 2010; DORNELAS, 2001; ETZKOWITZ, 2002 e TIMMONS, 2001.
}

INTRATEXTOS, Rio de Janeiro, 4(1): 137-159, 2012.

Página 145 
incubadoras é de que a formação de empresas pode ser melhorada ao se organizar como um processo educacional.

Segundo William Bolton (1997), as transformações em curso nos campos da economia do desenvolvimento empresarial e da educação assinalam para a introdução de novos modelos explicativos e propositivos que tenham maior sintonia com a realidade atual (os modelos existentes já não são adequados para explicar problemas e prover soluções). $O$ autor vê diferença significativa entre as grandes empresas tradicionais e as pequenas empresas de base tecnológica. As primeiras enfrentam dificuldades financeiras, ao passo que as últimas apresentam grande crescimento e suas ações se valorizam em níveis espantosos nas Bolsas.

Essa conjuntura é batizada pelo autor de enterprise paradigm e ressalta as afinidades da relação universidade/empresa. Nesse modelo explicativo, o elemento fundamental são as empresas de base tecnológica e a universidade tem papel de vanguarda, por apresentar a maior concentração de talentos intelectuais em qualquer setor. Ao mesmo tempo, a universidade, por conta de sua tradição e seu tamanho, processa as mudanças de forma lenta. Esse é um aspecto delicado do processo que, para Bolton, não tem meio termo no envolvimento da universidade: “ou ela exerce a liderança do processo ou ficará a reboque dos acontecimentos" (BOLTON, 1997, p. 18, tradução nossa).

Para Dornelas (2001), o contexto atual é propício para o surgimento de um número crescente de empreendedores. Para o autor, vários países, inclusive o Brasil, estão investindo na capacitação dos candidatos a empreendedor como uma prioridade. Há, também, uma preocupação/interesse cada vez maior das escolas e universidades sobre o assunto e isso se demonstra pela criação de cursos e disciplinas específicas sobre o empreendedorismo. A intenção é apresentar o empreendedorismo como uma alternativa para os jovens que se graduam em ensinos técnicos e universitários.

No livro O Segredo de Luísa, um dos personagens de Dolabela reflete sobre a importância do ensino do empreendedorismo e destaca que é preciso "fazer com que em todos os cursos, do primário à pós-graduação, exista sempre um conteúdo sobre a iniciativa, a independência, a criatividade, o conhecimento do mercado e de suas necessidades". Além disso, é necessário "mudar a visão dos cursos". Os estudantes de todos os cursos precisam saber empreender e não ficarem presos aos conhecimentos específicos de sua área. "A capacidade de criar algo só se aprende na ação e quando se tem um perfil para isso. E esse perfil pode ser adquirido" (DOLABELA, 1999a, p. 201). 
Um dos principais obstáculos ao desenvolvimento do empreendedorismo é assinalado por Dolabela (1999b) como a "síndrome do empregado". O profissional que é contaminado por essa "síndrome" necessita que alguém crie e lhe ofereça condições para que desenvolva o trabalho (depende de alguém para desenvolver seu ofício; executa o que os outros criaram). Para Dolabela (1999b), esse modo de ver o trabalho era útil no paradigma econômico que se esgotou. Segundo o autor, as universidades ainda perpetuam essa concepção em seus cursos de formação superior.

Para modificar isso, o aluno deve ter desde cedo contatos com a cultura empresarial.

[...] o verdadeiro locus do aluno empreendedor é o ambiente empresarial. Ali ele deve encontrar as relações e os conhecimentos indispensáveis ao sucesso do seu empreendimento. Igualmente, o laboratório do educador preocupado com o empreendedorismo é o ecossistema econômico-empresarial (DOLABELA, 1999b, p.45).

Simon Schwartzman, em uma entrevista publicada na Revista Veja, assinala a necessidade da aproximação da universidade (principalmente pública) com a empresa. Por seguirem a lógica do serviço público, as instituições de ensino superior não têm flexibilidade para pagar melhor um pesquisador em específico e nem para "tratar de forma diferenciada um departamento que tem potencial para produzir mais". Por isso, precisam ser mais flexíveis na administração (SCHWARTZMAN, 2008).

Por seu turno, as universidades têm de ser motivadas para buscar parcerias com empresas. Para Schwartzman (2008), as instituições precisam ganhar alguma coisa com isso, mas, também, têm de perder se não fizerem esforços para implementar projetos em conjunto com a iniciativa privada.

Vou dar uma sugestão. Se cada departamento da universidade recebesse apenas $50 \%$ do seu orçamento e tivesse de levantar os outros $50 \%$, já seria um grande estímulo. Poderia ser estipulado que o pesquisador receberá seu salário em dobro se o departamento conseguir mais dinheiro, mas receberá a metade se não conseguir nada. Isso os tiraria da inércia (SCHWARTZMAN, 2008, p. 14).

De acordo com a pesquisa realizada por Schwartzman, existem centros de pesquisa universitários na América Latina que conseguem associar ciência de excelência à relevância social ou econômica. Nessas universidades

O principal fator é o humano. Em todos os casos que estudamos, havia um pesquisador com mentalidade empresarial, que liderou o processo de integração com 


\begin{abstract}
o mercado. Mesmo nas universidades públicas, o líder de um departamento, além de ser bom na sua área, deve ter um perfil empreendedor. Precisa estar o tempo todo antenado com o que acontece fora da universidade para saber quais temas de pesquisa estão surgindo, quais as linhas mais promissoras e onde estão as oportunidades. Ele tem de saber convencer os outros da importância do seu trabalho. Isso cria uma dinâmica. [...] É preciso dar mais liberdade para que líderes de departamento com capacidade empreendedora possam agir (SCHWARTZMAN, 2008, p. 14).
\end{abstract}

Para Silvestre et al. (2008), da parte da academia, da coletividade científica, há pouco interesse no sentido de tornar seus membros empreendedores. Também, a habilidade e a formação empreendedoras são quase nulas entre cientistas, professores e alunos. Nesse sentido, os autores acrescentam que modificações precisam ser incluídas nos processos avaliativos sobre as pesquisas feitas pela universidade:

[...] é necessário que o sistema de avaliação de pesquisadores considere que o reconhecimento não seja apenas pela geração e transferência tradicional de conhecimento (via publicações), mas inclua itens como pedidos de registros de patentes e parcerias que visem ao empreendedorismo inovador e o consolidem (SILVESTRE et al., 2008, p. 26).

Em sentido contrário aos argumentos apresentados acima, o documento do ANDESSN (Sindicato Nacional dos Docentes das Instituições de Ensino Superior) sobre reforma da educação superior do governo Lula analisa criticamente a emergência da cultura do empreendedorismo no interior da universidade. Para os membros do ANDES-SN, Domingos Filho, Elen Castelo Branco, Maria Aparecida Moysés e Roberto Leher, autores do capítulo Inovação tecnológica e universidade, a origem desse processo da emergência do empreendedorismo nas instituições universitárias e de mercantilização da educação está ligada às transformações que ocorreram na educação de nível superior brasileira a partir dos anos 90, com forte influência da ideologia neoliberal (FILHO, et al., 2004).

Diante de uma cuidadosa reflexão, os supracitados autores acrescentam que tais transformações têm como base a aproximação da universidade com o setor produtivo e uma série de políticas governamentais que promovem uma aproximação crescente do meio acadêmico com o mercado ${ }^{5}$, desvirtuando o papel público, criativo e autônomo do meio universitário. Diante dessas questões, "os currículos devem ser flexíveis e assegurar a

\footnotetext{
${ }^{5}$ Em 2000, foi instituído o projeto de lei $\mathrm{n}^{\circ} 10.168$ que regulamentou a criação de um fundo setorial para incentivar a interação entre universidades e empresas no desenvolvimento cientifico e tecnológico brasileiro, o Fundo Verde e Amarelo. Em 2004 foi sancionada a lei $n^{\circ}$ 3.476, a lei da inovação, com objetivo de favorecer o investimento de empresas em pesquisa científica e tecnológica no país. No mesmo ano foi aprovada a lei ${ }^{\circ}$ 10.973, oficializando o estímulo à interação entre instituições científicas e tecnológicas e empresas.
}

INTRATEXTOS, Rio de Janeiro, 4(1): 137-159, 2012.

Página 148 
aquisição de competências imediatamente comercializáveis no mercado" (FILHO, et al., 2004, p. 44).

A universidade, então, segundo essa argumentação, passa a captar recursos no mercado, oferecendo como contrapartida (moeda de troca) serviços de inovação tecnológica, atividades que não podem ser conceituadas como próprias da universidade. Nesse contexto, esses processos, ao generalizarem esse modo de atuação, redefinem a própria função social das instituições e "[...] convertem o docente em um "empreendedor" que será remunerado conforme a sua capacidade empreendedora" (FILHO, et al., 2004, p. 46).

Essa relação é descrita da seguinte maneira pelo GEM (Global Entrepreneurship Monitor):

\begin{abstract}
Os empreendedores inovadores são aqueles que lançam produtos novos para todos os mercados e usam tecnologias desconhecidas, com expectativa de exportação e criação de empregos. São esses empreendedores que geram inovações radicais e são transformadores da economia e da sociedade. Esse tipo de empreendedor, idealmente, está vinculado a um sistema de inovação em ambientes com laboratórios avançados, é envolvido com grupos de pesquisadores vinculados a universidades e incubadoras tecnológicas e dispõe de apoio institucional, tais como financiamento, assessoria e consultoria, apoio técnico e mão-de-obra especializada. Na sociedade do conhecimento, a realização de empreendimentos altamente inovadores depende de ambientes propícios à inovação e de políticas públicas (industrial e tecnológica) fortemente focadas para reduzir os obstáculos e as dificuldades iniciais da implantação do empreendimento. [...] As políticas voltadas para os empreendedores inovadores, que desenvolvem inovações radicais, devem estar vinculadas à formação de incubadoras tecnológicas, ao aprofundamento da relação universidade-empresa, à criação de laboratórios de pesquisa, à formação de pesquisadores e grupos de pesquisa e ao financiamento ao capital de risco, entre outras ações (GEM, 2009, p. 74).
\end{abstract}

Assim, empreendedorismo e inovação passam a ser os dois vetores que conduzem a relação universidade-empresa. Formar empreendedores inovadores (sejam eles professores, alunos, técnicos, cientistas, entre outros) passa a ser um dos objetivos desse tipo de interação.

\title{
Estudo empírico em uma universidade pública: incubadoras de empresas e a penetração da cultura empresarial nas práticas do fazer científico ${ }^{6}$
}

A investigação desenvolvida é de natureza qualitativa e se trata de um estudo de caso realizado por meio de pesquisa empírica junto a gestores e cientistas-empreendedores localizados em duas incubadoras de empresas (biotecnologia e informática) situadas em uma

\footnotetext{
${ }^{6}$ A fonte dos dados apresentados neste tópico é, em sua maioria, a fala dos gestores e dos empreendedores (membros das incubadoras) e as informações contidas em sítios eletrônicos das empresas e das incubadoras de empresas relacionadas. Para maiores informações sobre a pesquisa ver: DOMINGUES, 2010.
}

INTRATEXTOS, Rio de Janeiro, 4(1): 137-159, 2012. 
universidade pública do Rio Grande do Sul. O grupo escolhido para a pesquisa é composto de 4 gestores (coordenadores acadêmicos/gerentes), 2 de cada incubadora, e de 6 cientistasempreendedores $^{7}$ (representantes de micro ou pequenas empresas), 3 de cada incubadora. No total, são 10 agentes escolhidos.

Para preservar a identidade dos atores entrevistados, bem como o nome da universidade e das incubadoras pesquisados, atribuem-se a eles nomes fictícios e identificações genéricas.

O fato de ser uma universidade pública implicou peculiaridades que distinguem, em alguns aspectos, a realidade pesquisada das representações apresentadas pela literatura especializada sobre a relação entre universidades e empresas.

Por essa razão, faz-se necessário destacar alguns traços singulares do objeto empírico, como, por exemplo, o de ser uma universidade pública, e não uma instituição de ensino particular (que facilitaria as relações entre universidade/empresa), as particularidades do processo de incubação de cada área, entre outras coisas. Nas pesquisas feitas sobre incubadoras de empresas, de modo geral, levam-se pouco em conta as limitações desse tipo de empreendimento numa realidade semi-periférica como a do Brasil. Boa parte da teoria é pensada, principalmente, nos exemplos estadunidenses, e alguns pesquisadores apenas a replicam, quando avaliam o campo brasileiro, com poucas adaptações ${ }^{8}$.

Há uma relação muito mais complexa no contexto da universidade pública. Os interesses são difusos, existe um grande número de grupos instituídos ou não que atuam no seu interior, nota-se "[...] a presença de opiniões, atitudes e projetos conflitantes que exprimem divisões e contradições da sociedade" (CHAUI, 2003, p. 5).

$\mathrm{O}$ atrito entre o privado e o público fez-se presente em vários momentos durante a pesquisa. Gerentes de incubadoras, professores sócios de empresas e outras pessoas,

\footnotetext{
${ }^{7}$ Cientista-empreendedor é a expressão encontrada para denominar esses agentes que ainda não se enquadram totalmente nas concepções que existem na literatura especializada sobre o empreendedor, que não se encaixam em seu perfil (ele ainda não é empreendedor; tem pouco contato com a prática dos negócios e de atuação no mercado). É o sujeito que tem formação acadêmica, mas não teve ainda contato com o mundo das empresas (gestão, marketing, vendas, etc.). O cientista-empreendedor está muito mais ligado à universidade do que ao mercado, apesar de estar sendo cada vez mais influenciado por esse último. Ele ainda é um acadêmico que está tomando contato com a cultura empresarial. Mas, além disso, essa expressão quer dar destaque a esse processo de encontro entre o mercado e a universidade e a forma como essas transformações modificam a maneira de pensar e de agir desses cientistas, engenheiros, professores universitários e alunos que passam pelo processo de incubação de empresas (versa sobre o cientista que está se transformando em empreendedor, que pensa e sonha com o sucesso, e que quer ver suas pesquisas gerarem bons negócios).

${ }^{8}$ Isso sem ressaltar as diferenças que existem no país entre as regiões (norte e sul), ou mesmo, entre capitais e grandes centros urbanos com o interior.
}

INTRATEXTOS, Rio de Janeiro, 4(1): 137-159, 2012.

Página 150 
explicitaram essas dificuldades, entre outros pontos, no que tange ao reconhecimento da coletividade científica, principalmente entre profissionais da mesma área epistêmica, sobre as atividades das incubadoras na universidade.

No campo da biotecnologia tal aspecto ficou mais evidente do que no da informática, mas, de modo geral, essa é uma preocupação que atinge as relações entre os dirigentes das incubadoras e os representantes/chefes de centros ou de departamentos acadêmicos.

A falta de legislação e de modelos jurídicos apropriada também é vista como um impedimento para o desenvolvimento desse tipo de atividade numa instituição pública. Já as universidades privadas teriam, na opinião dos pesquisadores entrevistados, mais facilidades para chamar empresas grandes por meio de renúncias fiscais e outros incentivos/garantias (como construírem prédios próprios na universidade), de modo a impulsionar as relações com parques tecnológicos e incubadoras, proporcionando uma relação mais direta e facilitada entre empresas, universidade e mercado.

Na universidade pública há um atrito maior entre o mundo acadêmico e o empresarial, apesar de existirem sólidas relações entre pesquisas de professores e interesses de grandes laboratórios e empresas, muitas vezes não-claras dentro do meio universitário. Mas a idéia de transformar professores e cientistas em empreendedores encontra mais resistência nas instituições públicas de ensino superior. Ao mesmo tempo, paradoxalmente, os maiores centros de incubação de empresas no Brasil estão em universidades públicas.

Apesar da resistência destacada, nas duas incubadoras pesquisadas foi possível perceber de forma significativa a penetração da cultura do empreendedorismo nas práticas das pessoas envolvidas (gestores e cientistas-empreendedores). As falas dos cientistasempreendedores ressaltaram mudanças por eles sentidas desde que se envolveram ativamente com o mundo empresarial. Gerentes e coordenadores acadêmicos expressaram de modo muito semelhante a importância do empreendedorismo para a consolidação da estrutura de incubação de empresas montada.

Os campos epistêmicos também possuem diferenças que ecoam significativamente nas práticas de cada incubadora. Por exemplo, a incubação de uma empresa de biotecnologia é muito mais longa que a de informática, em média de seis anos e que pode chegar a até dez anos, ao contrário dos três anos, tempo médio, de uma empresa de informática. Segundo os entrevistados, as entidades de capital de risco (venture capital) não financiam e nem investem 
no mercado de biotecnologia, pelo menos no Brasil. Já na área de informática, tal prática se faz mais presente. Uma das explicações seria o tempo de espera para o retorno financeiro.

De outra parte, Flávia (gerente) destaca que o mercado de biotecnologia no Brasil ainda é muito incipiente e que existem poucas empresas no ramo. "Qualquer coisa que se fizer em biotecnologia no Brasil tem mercado, porque tudo é importado" (Flávia, gerente da incubadora de biotecnologia). Há espaço para ter bons negócios, mas o investimento é muito alto. Por isso a gestora ressalta a importância dos recursos públicos a fundo perdido para o financiamento das empresas. Entre os setores em que as incubadoras de empresas atuam, o desenvolvimento de produtos em biotecnologia é o que mais precisa de investimentos em pesquisa e desenvolvimento (um quarto do faturamento).

A presença de professores universitários entre os sócios é mais visível nas empresas de biotecnologia. Também nesse campo, constata-se maior participação de alunos de pósgraduação nas atividades desenvolvidas pelas empresas. Bolsas de mestrado e doutorado são ofertadas aos alunos para que estes desenvolvam pesquisas relacionadas com os enfoques de atuação das empresas. As empresas formadas nesse campo do conhecimento decorrem, geralmente, de projetos e pesquisas já desenvolvidos no meio acadêmico e o campo de atuação delas, na maioria dos casos, são demandas de processos laboratoriais de pesquisadores de outras universidades e institutos de pesquisa.

Nas empresas de informática há um grau menor de presença de professores entre os membros e as relações com o programa de pós-graduação e com o meio acadêmico são mais distantes. Os produtos desenvolvidos na incubadora não são, em sua maioria, resultado de pesquisas de alunos ou professores dos meios acadêmicos vinculados à área. A despeito dessa diferença quando comparado à biotecnologia, a incubadora de informática tem uma conexão significativa, em termos gerais, com as pesquisas e os projetos do centro em que está instalada.

$\mathrm{Na}$ incubadora de informática a cultura empresarial vinculada ao mundo dos negócios está mais presente do que na de biotecnologia. A própria apresentação da incubadora em folhetos de propaganda dá destaque a fotos com homens engravatados, representando executivos de sucesso. Já na biotecnologia as fotografias de divulgação mostram mulheres de jaleco branco, manipulando microscópios e tubos de ensaio em laboratórios; chamam a atenção para o âmbito científico e tudo o que ele representa (qualidade, segurança, alto padrão, neutralidade, eficiência). 
A inserção das incubadoras na universidade já modificou consideravelmente as relações estabelecidas no meio acadêmico das duas áreas. Na biotecnologia essa aproximação foi mais constatada pelo crescente número de professores e de estudantes de pós-graduação que atuam nas empresas incubadas e pela interação que existe com o programa de pósgraduação como um todo (disciplinas específicas de empreendedorismo e de gestão de negócios estão sendo ministradas).

Outros dados demonstraram que a propagação da cultura do empreendedorismo ecoou em vários sentidos no interior da universidade, estando presente também em um novo curso de graduação da instituição de ensino superior.

Nota-se muito nas duas incubadoras a ideia de ser o dono do seu próprio negócio, de ser empregador e não mais empregado. Há também ações para que essa visão se difunda entre os centros em que as incubadoras estão inseridas. A incubadora é um agente político importante nesse processo.

Na área de biotecnologia da universidade pesquisada já se percebe alguma diferença nas práticas e ações do meio acadêmico por conta da influência da incubadora. Essa opção, por gerar inovação, por criar um produto ou serviço visando ao mercado, ganha mais adeptos nesse campo que já passou por algumas controvérsias e disputas de interesse. As relações da coletividade ganham cada vez mais um contorno mercadológico, mas a dinâmica ainda é lenta; as transformações vão se dando aos poucos.

As empresas observadas na incubadora de biotecnologia contam com salas (tanto para laboratórios como para escritórios) e estrutura gerencial organizada (maiores e mais preparadas do que as da informática). Em alguns casos, existem secretários e outras pessoas designadas para realizar tarefas burocráticas. No geral, os cientistas (professores, alunos, biólogos) é que têm de desenvolver essas capacidades, em conjunto com outras requeridas: gestão/administração de finanças e de pessoas, compreensão sobre as oscilações do mercado e noções sobre relações de comércio, marketing e vendas. A característica de ter de saber um pouco de tudo é ainda mais acentuada entre os cientistas-empresários da incubadora de informática.

Nesta incubadora, não foi identificada uma relação tão próxima com a pós-graduação. Apesar desse fato, constatou-se, pelas entrevistas, uma rede de conexões significativa entre a incubadora e o centro de informática/computação da universidade. Ainda assim, os projetos não tiveram, em sua maioria, origem vinculada à área representativa da incubadora 
(informática/computação). Encontraram-se, entre os sócios das empresas, pessoas formadas nos mais diversos cursos: letras, administração, engenharias, etc. Tais indivíduos viram na incubadora um bom espaço para transformar ideias em negócios.

$\mathrm{Na}$ incubadora de informática há uma relação mais direta com os negócios. O interesse vinculado aos fatores econômicos é bem mais explícito do que na incubadora de biotecnologia. Nesta ainda há alguma resistência em tocar em certos assuntos e muito cuidado na forma de falar. $\mathrm{Na}$ incubadora de informática essa cultura empresarial se faz bem mais presente. Os cientistas-empreendedores se portam abertamente como homens de negócios, que buscam formas mais eficientes e eficazes de ganhar mais.

Mesmo com o apoio e o suporte, os problemas que um empreendimento novo tem de enfrentar são muitos: índice muito elevado de empresas que não resistem aos primeiros anos, necessidade de investir em pesquisa e desenvolvimento para melhorar constantemente o produto (ou para encontrar/criar novos nichos de mercado), falta de recursos, dedicação exclusiva à empresa, incertezas de sucesso, prazos muito curtos, entre outros. Para superar essas dificuldades de toda ordem, professores, alunos e cientistas não estão preparados, a discrepância com o mundo empresarial é muito grande.

As incubadoras, então, estimulam o empreendedorismo por meio de palestras, cursos e outras formas de incentivo direto para desenvolver em professores, alunos, cientistas e engenheiros o espírito empreendedor. Os consultores de mercado também influenciam bastante e encorajam os jovens empreendedores a agirem enquanto tais. Esse apoio fornece contatos com pessoas da área jurídica (trabalhista, tributária), de gerenciamento de processos de negócios, de segurança do trabalho, de recursos humanos, etc.

É preciso fazer esse trabalho de transição entre essas duas instâncias (acadêmica e empresarial). Tal fato influencia diretamente na forma de os membros das empresas conceberem o que fazem e sua relação com o conhecimento. A partir do contato com a incubadora, a cultura de negócios e de gestão passa a ter peso significativo em todas as decisões tomadas pelos cientistas-empreendedores. Vários foram os relatos em que se nota a mudança de comportamento dos atores antes e depois de iniciado o processo de incubação.

Segundo explicações dos gestores, é por falta de contato dos sócios das empresas com o mundo do mercado que essas capacidades empreendedoras e de gestão de negócios acabam sendo as mais desenvolvidas no processo de incubação. Mas, muito pouco se escuta no interior da incubadora sobre outros assuntos que não se refiram ao universo empresarial. 
Professores, alunos, cientistas e engenheiros que até pouco tempo tinham foco em pesquisa científica e em relações acadêmicas com a universidade, passam a preocupar-se com capital de giro, com concorrência/competitividade e com estratégias para ganhar mercado.

O discurso sobre o sucesso, tanto financeiro quanto em outros âmbitos, esteve presente em algumas entrevistas, mais notado nas da incubadora de informática. Em alguns pontos os cientistas-empreendedores chegavam a dizer, comentando sobre seus projetos futuros, "isso dá muito dinheiro!”. Em outros momentos, comparações com grandes empresas que surgiram de boas ideias eram constantes. No geral, apesar das complicações enfrentadas, muitos acreditavam estar na trilha de um sucesso alcançável, por vezes repentino, fruto de alguma novidade que ainda estava para surgir.

Os ícones desses cientistas-empreendedores eram as mais lucrativas empresas do ramo de informática/comunicação/entretenimento. Nelas, eles se espelhavam para encontrar novos ramos de mercado ou subverter os já existentes. Entre a realização desse anseio e o enfrentamento das dificuldades objetivas havia uma longa distância, com obstáculos por vezes intransponíveis.

Toda a pressão e a busca constante pelo dinheiro, marcas do empreendedor já estabelecido no mercado, já se fazem notar, em alguma medida, durante o processo de incubação. Apesar da segurança/apoio na incubadora, o cientista-empreendedor sabe que o momento de enfrentar o mercado está cada vez mais próximo. As esperanças de sucesso dele estão depositadas exclusivamente no produto ou serviço projetado (razão pela qual a empresa está incubada, para desenvolver um produto tecnologicamente inovador).

\section{Considerações finais}

Este artigo avaliou, partindo de um estudo empírico, como as recentes transformações da prática dos pesquisadores de universidades públicas estão vinculadas a emergência da cultura do empreendedorismo no interior das próprias instituições de ensino. $\mathrm{O}$ pesquisador/professor que trabalha com pesquisa na universidade não encontra mais as mesmas condições de trabalho de décadas atrás. Exigências externas ao meio universitário sobre a mudança da postura do pesquisador, explicitando o alinhamento deste às demandas do mercado estão cada vez mais presentes no interior do meio acadêmico. 
Trata-se, portanto, de um processo de transformação das noções clássicas que são associadas aos cientistas (neutralidade, autonomia, objetividade) para as atribuições que esse novo momento demanda e que estão próximas de um perfil empreendedor (vinculação estreita com o mercado, pró-atividade, liderança).

Nesse sentido, com essa prática mais vinculada ao mercado, o cientista precisa desenvolver habilidades e competências próprias do universo dos negócios. O empreendedorismo torna-se a forma de conhecimento e de desenvolvimento dessas capacidades empresariais, encontrando nos meios acadêmicos um terreno fértil para a expansão de sua visão de mundo. Pensar e agir segundo os parâmetros do empreendedorismo passou a ser o empenho de muitos cientistas e pesquisadores. Busca-se a figura do empreendedor de sucesso, aquele que é arrojado e criativo, que assume riscos e toma iniciativas, que tem qualidades de liderança.

Especificamente, o trabalhou avaliou empiricamente um dos lócus privilegiados desse processo de transformação: as incubadoras de empresas. Elas são um dos enfoques das teorias que reivindicam uma aproximação maior entre universidades e empresas. Os exemplos de pequenas empresas de inovação tecnológica, principalmente estadunidenses, surgidas desses ambientes e que conquistaram o mercado global são os exemplos mais ressaltados pela literatura especializada: Aple, Google, eBay, Microsoft, Hewlett-Packard, entre outras.

Um dos problemas de importar essa visão sem as devidas adequações sócio-históricas é que as mesmas condições materiais não se apresentam em solo brasileiro. Ser um empreendedor aqui não é a mesma coisa de ser empreendedor nos Estados Unidos. A configuração das universidades também é diferente, assim como seus meios de incentivo e de financiamento.

Ainda assim, a aproximação da universidade com o mundo empresarial encontrou na incubadora de empresas um dos arranjos mais bem pensados para incutir em professores, alunos, engenheiros e cientistas a necessidade de se tornarem empreendedores (empresários donos de seus negócios) e incentivar a produção de inovação tecnológica com interesse no mercado.

Essas transformações de mentalidade, de prática e de organização dos cientistasempreendedores demonstram um princípio/início da penetração do empreendedorismo no ambiente universitário investigado. Por se tratar de uma análise a partir de uma instituição pública, pode-se arriscar a inferir, pela crescente expansão das incubadoras de empresas no 
país, que esse processo se reproduza, com outras características e ritmos, em outras universidades de expressão nacional ou regional, tanto em públicas como, principalmente, nas privadas.

As incubadoras de empresas representam a materialização de alguns processos de modificação das relações da universidade com a sociedade, especificamente no que diz respeito à constituição de empresas de alta tecnologia no interior de centros acadêmicos. Esses movimentos de mudança também dizem respeito a transformar cientistas, professores universitários, engenheiros ou alunos de pós-graduação em jovens empresários, e incutir neles uma mentalidade empreendedora para poderem criar/encontrar posições estratégicas em um mercado cada vez mais volátil e de muita concorrência.

\section{Referências Bibliográficas}

BOLTON, W. The university handbook on enterprise development. Paris: Columbus Handbooks, 1997.

CÊA, G. S. S.; LUZ, A. S. Empreendedorismo e educação: reflexões sobre o velho sonho liberal. Revista Espaço Acadêmico, n.63, Ano VI, ago, 2006.

CHAUI, M. A universidade pública sob nova perspectiva. Revista Brasileira de Educação, n. 24, set/out/nov/dez, 2003.

DOLABELA, F. O segredo de Luísa: uma idéia, uma paixão e um plano de negócios - como nasce o empreendedor e se cria uma empresa. São Paulo: Cultura Editores Associados, 1999a.

DOLABELA, F. A oficina do empreendedor: a metodologia de ensino que ajuda a transformar conhecimento e riqueza. 6. ed. São Paulo: Ed. de Cultura, 1999 b.

DOMINGUES, L. L. S. A produção tecnológica em incubadoras de empresas. 2010. 167f. Dissertação (Mestrado em Sociologia). UFRGS, Instituto de Filosofia e Ciências Humanas, Porto Alegre, 2010.

DORNELAS, J. L. A. Empreendedorismo: transformando idéias em negócios. Rio de Janeiro: Campus, 2001.

INTRATEXTOS, Rio de Janeiro, 4(1): 137-159, 2012. 
DRUCKER, P. F. Inovação e espírito empreendedor (entrepreneurship): prática e princípios. Trad. Carlos J. Malferrari. São Paulo: Pioneira, 1986.

ETZKOWITZ, H. Reconstrução criativa: hélice tripla e inovação regional. Rio de Janeiro: Inteligência Empresarial/CRIE/COPPE/UFRJ, n. 23, 2005.

ETZKOWITZ, H. The rise of the entrepreneurial university. 2002. Disponível em: http://www.stanford.edu/dept/HPS/TimLenoir/Startup/VolumeDrafts/UnivInd_Bkgrnd/EtzkowitzPaper.pdf . Acesso em: 20 jan. 2010.

FILHO, D. L. L. et al. Inovação tecnológica e universidade. In: GTPE/ANDES-SN. A contrareforma da educação superior: uma análise do ANDES-SN das principais iniciativas do governo Lula da Silva. Brasília: GTPE/ANDES-SN, 2004.

GEM. Empreendedorismo no Brasil. Curitiba: IBPQ, 2008. Global Entrepreneurship Monitor.

GEM. Empreendedorismo no Brasil. Curitiba: IBPQ, 2009. Global Entrepreneurship Monitor.

GOUVEIA, T. B. A demanda empreendedora e o trabalho imaterial na construção da subjetividade do "empreendedor". 2006. 157f. Dissertação (Mestrado em Administração) Universidade Federal do Rio Grande do Sul, Porto Alegre, 2006.

LIMA, A. L.; ARELARO, L. R. G. Empreendedorismo e vulnerabilidade dos trabalhadores empobrecidos. 2008. Disponível em:

http://www.porto.ucp.pt/lusobrasileiro/actas/Aguinaldo\%20Lima.pdf . Acesso em: 10 out. 2009.

PAES DE PAULA, A. P. Tragtenberg revisitado: as inexoráveis harmonias administrativas. 2000. Disponível em:

http://abrad.org.br/login.php?cod_edicao_subsecao $=51 \&$ cod_evento_edicao $=4 \& \operatorname{cod} e d i c a o \_t$ rabalho=4307 . Acesso em: 05 dez. 2009.

PNUD. Desencadeando o empreendedorismo: o poder das empresas a serviço dos pobres. Relatório para o Secretário Geral das Nações Unidas. New York: PNUD, 2004.

SCHWARTZMAN, S. É preciso ir à luta. Revista Veja, n. 2059, p.11-15, maio, 2008. SILVA, L. F.; BASSANI, C. L. Evolucionismo: a face oculta do empreendedorismo. 
Brazilian Business Review, v.4, n.1, p.60-73, jan/abri, 2007.

SILVESTRE, R. G. M. et al. Empreendedorismo inovador: perfil atual do empreendedorismo brasileiro segundo o Global Entrepreneurship Monitor. In: PAROLIN, S. R. H.; VOLPATO, M. (Orgs.). Faces do empreendedorismo inovador. Curitiba: SENAI/SESI/IEL, 2008. Coleção inova, v.3.

TIMMONS, J. A. New venture creation: entrepreneurship for the 21st century. Boston: McGraw-Hill/Irwin, 2001.

VASCONCELLOS, E.; WAACK, R.; VASCONCELLOS, L. Inovação e competitividade . 1997. Disponível em:

http://www.anpad.org.br/login.php?cod_edicao_subsecao $=149 \& \operatorname{cod}$ evento_edicao $=1 \& \operatorname{cod}$ edicao_trabalho=3786 . Acesso em 15 jan. 2010.

WORLD BANK. Globalization, growth and poverty: building an inclusive world economy. New York: Oxford University Press, 2002. 